when protesters against GM crops have promised to turn up in force and destroy the experimental plots.

The protest group, it must be acknowledged, has a great name Take the Flour Back. And it no doubt believes that it has the sympathy of the public. The reputation of GM crops and food in Britain, and in much of mainland Europe, has yet to recover from the battering it took in the late 1990s. In Germany, the routine destruction of crops by protesters has meant that scientists there simply don't bother to conduct GM experiments any more.

The Rothamsted scientists have also attempted to win over the public, with a media campaign that explains what they are trying to do and why. After the protesters announced their plans to "decontaminate" the research site, the scientists tried to engage with their opponents, and pleaded with them to "reconsider before it is too late, and before years of work to which we have devoted our lives are destroyed forever". The researchers say that in this case they are the true environmentalists. The modified crop, if it works, would lower the demand for environmentally damaging insecticides.

As Nature went to press, the stalemate continued. The GM crop at Rothamsted remains, but so does the intention of the protesters to destroy it.

There are very real consequences to this kind of protest. German chemical giant BASF this year announced that it would move its transgenic plant operations from Europe to the United States, in part because of the perception of continuing widespread opposition to GM crops in Europe. And although farmers in other parts of the world have taken to GM crops with gusto, Europe, with some exceptions, misses out. Evidence suggests that it is missing a lot. The adoption of herbicide-resistant oilseed rape has reduced the use of herbicides by farmers in North America, and also reduced tillage, which has its own environmental benefits. The adoption of pest-resistant GM cotton has lowered the use of pesticides. Nevertheless, the reasons for the hostility towards genetic modification in Europe are clear. Justifiable unease over the way in which GM-led business models would hand entire food chains to large agrochemical companies found a popular proxy in less-realistic concerns over the possible health impacts of the new technology.

But with the world's population now at 7 billion and counting, the
"To destroy experiments before the outstanding questions can be answered is more than local vandalism, it is recklessness on a global scale." rejection of genetic modification of crops on such spurious scientific grounds now threatens the environment it claims to protect. To feed a population likely to top 9 billion in 2100 , we are going to need to change the way we grow our food. Harking back to oldfashioned methods and talking up organic farming will not do it. Genetic modification alone will not do it, but it could be a crucial tool and one that it is foolish to oppose on sentimental or ideological grounds.

This will not convince diehard opponents, of course, just as pleas for the value of scientific research failed to sway the criminal faction of the animal-rights movement. But, just as it proved with animal rights, it is far from clear that GM protesters, however many turn up at Rothamsted in a fortnight, truly attract public support.

GM crops could significantly reduce the use of pesticides, herbicides and fertilizers, and provide greater tolerance to a more extreme climate. True, we are still in the early stages of this technology. And there are some legitimate concerns, such as possible leakage of GM material into the local environment. But to destroy experiments such as the one at Rothamsted before the outstanding questions can be answered is more than local vandalism, it is recklessness on a global scale.

\section{Price of freedom}

\section{The latest mission to Jupiter highlights the benefits and pitfalls of collaboration.}

$\mathrm{I}$ $\mathrm{t}$ is a long trip to the outer reaches of the Solar System. Planetary scientists who are eager to explore Jupiter and the planets beyond tend to plan their experiments not in terms of years, but generations. And so it is with some rejoicing, and also relief, that they have another mission on the books.

Last week, the European Space Agency (ESA) announced that it had selected the Jupiter Icy moons Explorer, or JUICE, a solar-powered behemoth that, at 4.8 tonnes, would be the heaviest interplanetary probe ever flown by Europe. It would launch in 2022 and arrive at Jupiter almost eight years later. After a few flybys of Jupiter's moons Callisto and Europa, in 2032 the probe would settle into orbit around its primary target, the moon Ganymede, for at least a year of science. Ganymede's main mystery is its enigmatic magnetic field, the only moon in the Solar System to have one. But, like Europa, Ganymede also has a subsurface ocean although one that is less enticing to astrobiologists because it is likely to be isolated, sandwiched between thick layers of ice that prevent interesting chemical interactions with the surface and the deep rocky mantle.

Still, JUICE came top in a competition that sent two other prospective European missions packing. One was an X-ray telescope that would have imaged objects such as black holes with greater precision and sensitivity than ever before. Another was a set of satellites that, flying in formation, would have sensed tiny ripples in the fabric of space caused by violent events such as black-hole mergers - thereby opening up a whole new field: observational gravitational-wave astronomy.

Neither mission was a dud scientifically; quite the opposite. The gravitational-wave mission, in particular, is viewed as representing a scientific revolution in the making. These missions failed in the competition because they were expensive, and were likely to bust ESA's budget of $€ 1$ billion (US $\$ 1.3$ billion). And the reason ESA could not afford them was because both were originally designed as joint missions with the United States. When NASA pulled out, each mission tried to reduce its scope and lower its price tag, but that proved too difficult.

JUICE was also once married to a NASA mission, but in a more modern arrangement. The ESA mission would have had its own satellite and rocket launcher, as would NASA, which would have sent an orbiter devoted to studying Europa. When the budgetary rug was pulled out from under NASA's Europa orbiter, JUICE was in much better shape, politically and financially.

The lessons here would seem to be perverse: eschew tight collaborations and you will be rewarded for your independence. Avoid working with foreign agencies and you will be better off in the long run.

That might be true, but only from the perspective of a scientist interested in Ganymede - and only Ganymede. Without NASA involvement, plenty of Europan science has been lost. And had the two missions launched as a loose partnership, there would have been several ways in which the sum of the two missions was greater than its parts. For example, tracking the magnetosphere of the Jovian system using two probes makes a far better map than using just one.

The bigger point, however, is that the frontiers of science in many fields are reaching the stage - or price tag — at which no single country can go it alone. Just ask scientists who worked on completing the Human Genome Project, or building the Large Hadron Collider near Geneva, Switzerland. Of late, space scientists at NASA and ESA have no such project to hold up as an example. In addition to the X-ray and gravitational-wave observatories, other transatlantic partnerships have $\checkmark$ NATURE.COM To comment online, click on Editorials at: go.nature.com/xhunqv evaporated, including ones to study dark energy and to return samples from Mars. If a mission to the king of the planets is a cause for rejoicing, then the fact that it is so singular may be a cause for alarm. 